\title{
New Zealand Physiotherapists' and General Practitioners' Treatment Knowledge and Referral Decisions for Knee Osteoarthritis: A Vignette-based Study
}

Daniel W. O'Brien PhD

Senior Lecturer, Department of Physiotherapy; Active Living and Rehabilitation: Aotearoa New Zealand, Health and Rehabilitation Research Institute, School of Clinical Sciences, Auckland University of Technology, Auckland, New Zealand

Richard J. Siegert $P h D$

Department of Psychology and Rehabilitation, Auckland University of Technology, Auckland, New Zealand

Sandra Bassett $P h D^{*}$

Department of Physiotherapy, Auckland University of Technology, Auckland, New Zealand

Jennifer N. Baldwin PhD

Postdoctoral Fellow, Priority Research Centre in Physical Activity \& Nutrition, Faculty of Health and Medicine, The University of Newcastle, Australia

Valerie Wright-St Clair $P h D^{*}$

Professor, Department of Occupational Therapy, Auckland University of Technology, Auckland, New Zealand

*Has retired since completion of this study.

\section{ABSTRACT}

Physiotherapists' and general practitioners' (GPs) treatment knowledge affects the management of people with knee osteoarthritis $(\mathrm{OA})$, but little is known about the OA referral decisions and treatment knowledge of these clinicians in New Zealand. Data were collected from New Zealand registered physiotherapists and GPs $(n=272)$ using an online vignette-based questionnaire. Approximately two-thirds $(63 \%, n=172)$ of participants stated they would likely refer the hypothetical patient with knee OA to another profession. Participants indicated they would refer the woman between the two professions ( $73 \%, n=57 \mathrm{GPs}$ would refer to a physiotherapist; $47 \%, n=92$ physiotherapists would refer to a GP). However, few participants indicated they would refer the woman to other health professionals (such as 19\%, $n=52$ would refer to a dietitian). The majority of participants reported they would recommend education $(98 \%, n=267)$, therapeutic exercises $(92 \%, n=251)$ and weight-loss advice (87\%, $n=237$ ) as treatments for knee OA. These results indicate that first-line knee OA treatment knowledge of New Zealand GPs and physiotherapists are generally in keeping within international guidelines. However, promoting interprofessional collaboration with other health professions, such as dietetics, and providing education regarding treatments not recommended for OA is needed to meet all first-line treatment recommendations.

O'Brien, D. W., Siegert, R. J., Bassett, S., Baldwin, J. N., \& Wright-St Clair, V. (2021). New Zealand physiotherapists' and general practitioners' treatment knowledge and referral decisions for knee osteoarthritis: A vignette-based study. New Zealand Journal of Physiotherapy, 49(3), 118-126. https://doi.org/10.15619/NZJP/49.3.02

Key Words: General Practitioners, Knee Joint, Knowledge, Osteoarthritis, Physiotherapists, Treatment

\section{INTRODUCTION}

Osteoarthritis (OA) is a chronic musculoskeletal condition that can affect a person's physical, spiritual, social and mental wellbeing (Ackerman et al., 2015; Hochberg et al., 2015; McGruer et al., 2019). Hip and knee joint OA is currently ranked as the 11th highest contributor to disability worldwide (Cross et al., 2014). In New Zealand, OA affects nearly one in 10 people, and it was estimated that in 2018 arthritis cost the country approximately $\$ 12.2$ billion (Deloitte Access Economics, 2018). International evidence-based practice guidelines recommend that OA treatment options progress from conservative interventions (such as dietary changes and exercise) to invasive treatments (e.g., joint replacement surgery) (Allen et al., 2016; Bennell, 2013; Hunter, 2017). Furthermore, OA treatment should be multi-faceted and reflect the different ways the disease can affect the individual, including physically, socially and psychologically (Brosseau et al., 2016; Larmer et al., 2014; National Institute for Health and Care Excellence, 2015).

International management guidelines advocate for a staged approach to treatment progressing from first-line (exercise, education and weight loss if appropriate) to second-line treatments (pharmaceutical, aids or bracing and injection therapy) and third-line treatments (joint replacement surgery) (McAlindon et al., 2014; National Institute for Health and Care Excellence, 2015). A large component of the first-line conservative management of OA occurs in primary care; in New Zealand, this care is typically provided by physiotherapists and general practitioners (GPs) (Baldwin et al., 2017). Recent 
research indicates that GPs are generally the first point of care for most New Zealanders with OA (Jolly et al., 2017; Larmer et al., 2019). Furthermore, research suggests that first-line management approaches such as education, exercise and weight loss (if appropriate) are under-utilised internationally (Bennell et al., 2014; Healey et al., 2018; Hunter, 2011, 2017). The reasons for this are unclear but may include problems such as negative patient beliefs about these interventions, poor adherence or under-prescription by clinicians (O'Brien, 2018). Internationally, research has suggested that some clinicians' views contrast with international guidelines, and treatments offered frequently do not reflect the recommendations. Recent studies in New Zealand indicate similar findings from a patient's perspective (Jolly et al., 2017; Larmer et al., 2019; McGruer et al., 2019). However, little is currently known about OA treatment knowledge and referral decisions from a clinician's perspective and to what extent this knowledge and behaviour align with international practice guidelines.

There are several different methods for exploring clinical practice. Clinical vignette is one method for measuring clinical knowledge and self-reported behaviour, and has been previously used in this population (Holden et al., 2008). Clinical vignettes are cost-effective and allow for data to be collected efficiently from a wide range of clinicians (Evans et al., 2015; Peabody et al., 2004). However, caution should be applied when considering the findings, as clinical vignettes are prone to response bias (participants providing answers they believe the researcher wants to hear or believe are 'correct') and may not reflect actual clinical practice (Evans et al., 2015).

This study aimed to investigate the referral decisions and treatment knowledge of physiotherapists and GPs about New Zealanders with knee OA.

\section{METHODS}

\section{Study design}

This study was a cross-sectional, observational study with data collected via online questionnaires. Ethical approval to conduct this study was obtained from the Auckland University of Technology Ethics Committee (reference number 16/284).

\section{Participants}

Clinicians were eligible to participate if they were registered and practising in New Zealand as either a physiotherapist or GP, had treated a patient with knee OA in the past 6 months, were living in New Zealand at the time of data collection and had sufficient English language skills to complete the survey.

\section{Measures/questionnaires}

The survey comprised two sections: 1) demographic and occupational characteristics and 2) referral decisions and treatment knowledge about knee joint OA.

Section 1 collected demographic data about the participant, such as occupation and gender, as well as data about occupational characteristics, such as duration of practice and geographical location of the practice. Additionally, the occupational characteristics included questions about OAspecific practice such as, 'In your current job, how many patients do you see in your clinic/department with OA?' and 'What are the criteria that you typically used to decide that a person has OA of the knee joint?

The vignette used in the current study describes a 'typical' person presenting in a primary care setting for treatment of their knee OA, as well as a series of practice-based questions (Appendix A). The original vignette was based on the research records of an anonymous patient who had clinical knee OA, and the questions were based on those used by Holden et al. (2008), altered for use with both physiotherapists and GPs. The questions sought to understand how the practitioner believed they would manage the person. Before the survey was administered, all questions were tested for face validity and readability. Three clinical researchers with experience in OA research and survey design read the questionnaire and provided feedback about survey length, appropriateness for the New Zealand context and readability.

Procedure

The anonymised survey was advertised through several channels: physiotherapy continuing education courses, the Physiotherapy New Zealand Conference, the Royal New Zealand College of General Practitioners e-newsletters and the local primary healthcare organisation. Data were collected between 1 September and 1 December 2016 via SurveyMonkey® (https:// www.surveymonkey.com). Participants were required to read the online participant information sheet and respond to the items in the questionnaire. Submission of the questionnaire constituted informed consent to participate. No identifying information was collected, and participants could not be identified or traced.

\section{Data analysis}

All data were analysed using SPSS version 24.0 (IBM, USA), with the alpha level set at $p<0.05$. The use of the online platform limited missing data because participants were directed by automatic prompts to complete any missed item or question. Only complete data sets were analysed. It was not possible to calculate the total return rate for the survey, as participants completed the study online and it was unknown how many potential participants saw the study advertisement but chose not to participate.

\section{Demographic and occupational characteristics}

All data describing demographic and professional characteristics were categorical. For each category, the total number of scores was described using descriptive statistics. Data from GPs and physiotherapists were presented together and separately to allow comparison between the two professions. Categories that represented a small number of participants were collapsed into a single category, called 'Other'. Group equivalency between the two professions for demographic and occupational characteristics data were assessed with chi-square tests (Pallant, 2011). The Yates correction for continuity was reported where data were represented as a two-by-two assessment (Pallant, 2011).

\section{Clinical vignette data}

All data were categorical, so the total number of scores for each category were counted and converted to a percentage score of the total number of people who answered the question. Data from GPs and physiotherapists were presented as a single 
group and separately to allow comparison between the two professions. Group equivalence of the vignette question data between the two professions was assessed by Chi-Square tests. Where data represented a two-by-two test, the Yates' Continuity Correction was reported (Pallant, 2011).

\section{RESULTS}

\section{Demographic and occupational characteristics}

In total, 295 clinicians participated in this study and completed the demographic and occupational characteristics section of the survey (Table 1). The dropout rate from those who started the survey was $7.8 \%$, and 272 participants completed the clinical vignette. Approximately $70 \%$ of participants were physiotherapists. More female $(62.4 \%)$ than male participants completed the survey, irrespective of profession. The duration of practice ranged from less than five years to over 20 years in both professional groups. Significantly more physiotherapists than GPs had completed pre-registration qualifications in New Zealand $\left(X^{2}(1)=7.65, p=0.0001\right)$. Participants from both professions came from a range of geographical and employment settings. Significantly more GPs worked in private practice, whereas more physiotherapists worked in the public system.

\section{General OA patient referral decisions}

Table 2 shows that GPs saw significantly more people with knee OA more frequently than physiotherapists $\left(X^{2}(3)=27.67\right.$, $p=0.0001)$. Additionally, a significantly higher percentage of GPs indicated that they would commonly refer people with OA to other health professionals $\left(X^{2}(1)=16.39, p=0.0001\right)$. Most commonly, participants indicated that they would refer patients with OA to orthopaedic surgeons, radiographers/ sonographers and Green Prescription. Significantly more GPS indicated that they referred patients to these professions than physiotherapists did (orthopaedic surgeons: $X^{2}(1)=26.95, p>$ 0.000 ; radiographers/sonographers: $X^{2}(1)=32.48, p=0.0001$; Green Prescription: $\left.X^{2}(1)=11.61, p=0.001\right)$. Conversely, a much smaller number of participants indicated that they usually referred patients with OA to other professions such as dietitians or psychologists.

Vignette referral decisions and treatment knowledge Data from 272 participants were analysed (Table 3), and the results of the vignette questions are presented for the whole sample and the individual professions. The findings show that significantly more GPs indicated that they would refer the person described in the vignette to another clinician $\left(X^{2}(1)=\right.$

\section{Table 1}

Participants' Demographic and Occupational Characteristics ( $N=295$ )

\begin{tabular}{|c|c|c|c|c|c|c|}
\hline \multirow{2}{*}{ Characteristic } & \multicolumn{2}{|c|}{ All } & \multicolumn{2}{|c|}{ GPS } & \multicolumn{2}{|c|}{ Physiotherapists } \\
\hline & $n$ & $\%$ & $n$ & $\%$ & $n$ & $\%$ \\
\hline Participants & 295 & 100 & 87 & 30 & 208 & 70 \\
\hline \multicolumn{7}{|l|}{ Gender } \\
\hline Male & 111 & 38 & 39 & 54 & 72 & 35 \\
\hline Female & 184 & 62 & 48 & 55 & 136 & 65 \\
\hline \multicolumn{7}{|l|}{ Duration in practice } \\
\hline$<5$ years & 60 & 20 & 9 & 10 & 51 & 25 \\
\hline $6-10$ years & 63 & 21 & 20 & 23 & 43 & 21 \\
\hline $11-15$ years & 38 & 13 & 11 & 13 & 27 & 13 \\
\hline $16-20$ years & 38 & 13 & 8 & 9 & 30 & 14 \\
\hline$>20$ years & 96 & 33 & 39 & 45 & 57 & 27 \\
\hline \multicolumn{7}{|c|}{ Location of pre-registration qualification } \\
\hline In New Zealand & 217 & 74 & 54 & 62 & 163 & 78 \\
\hline Elsewhere & 78 & 26 & 33 & 38 & 45 & 22 \\
\hline \multicolumn{7}{|c|}{ Location of clinical practice } \\
\hline City & 197 & 67 & 54 & 62 & 143 & 69 \\
\hline Town & 63 & 21 & 17 & 20 & 46 & 22 \\
\hline Rural & 35 & 12 & 16 & 18 & 19 & 9 \\
\hline \multicolumn{7}{|l|}{ Employment setting } \\
\hline Public & 51 & 7 & 4 & 5 & 47 & 23 \\
\hline Private & 218 & 74 & 74 & 85 & 144 & 69 \\
\hline Both & 15 & 5 & 6 & 7 & 9 & 4 \\
\hline Other a & 11 & 4 & 3 & 3 & 8 & 4 \\
\hline
\end{tabular}

Note. For clarity, percentages are rounded to the nearest whole number. GP = general practitioner.

a Other employment settings included: aged care $(n=1)$, community care service $(n=2)$, hospice care $(n=1)$, Māori health trust $(n=2)$, occupational health service $(n=1)$, primary health organisations $(n=2)$ and university clinic $(n=2)$. 
Table 2

Participants' OA Patient Referral Decisions

\begin{tabular}{|c|c|c|c|c|c|c|}
\hline \multirow[t]{2}{*}{ Characteristic } & \multicolumn{2}{|c|}{$\begin{array}{c}\text { All } \\
(n=295)\end{array}$} & \multicolumn{2}{|c|}{$\begin{array}{c}\text { GPS } \\
(n=87)\end{array}$} & \multicolumn{2}{|c|}{$\begin{array}{l}\text { Physiotherapists } \\
\quad(n=208)\end{array}$} \\
\hline & $n$ & $\%$ & $n$ & $\%$ & $n$ & $\%$ \\
\hline \multicolumn{7}{|c|}{$\begin{array}{l}\text { Frequency of treating patients with hip and/or knee } \\
\text { osteoarthritis }\end{array}$} \\
\hline$\geq 1$ per day & 81 & 28 & 35 & 40 & 46 & 22 \\
\hline 1-3 per week & 121 & 41 & 43 & 49 & 78 & 38 \\
\hline $1-3$ per month & 66 & 22 & 8 & 9 & 58 & 28 \\
\hline $1-3$ in the past 6 months & 27 & 13 & 1 & 1 & 26 & 13 \\
\hline \multicolumn{7}{|c|}{ Usually refer patients with osteoarthritis to a(n) } \\
\hline 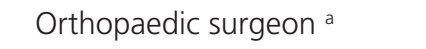 & 190 & 64 & 76 & 87 & 114 & 55 \\
\hline Radiographer/sonographer a & 130 & 44 & 61 & 70 & 69 & 33 \\
\hline Green Prescription ${ }^{a}$ & 120 & 41 & 49 & 65 & 71 & 34 \\
\hline Dietitian & 57 & 19 & 18 & 21 & 39 & 19 \\
\hline Occupational therapist & 44 & 15 & 14 & 16 & 30 & 14 \\
\hline Personal trainer ${ }^{a}$ & 39 & 13 & 4 & 5 & 35 & 17 \\
\hline Orthotist & 37 & 12 & 8 & 9 & 29 & 14 \\
\hline Psychologist & 15 & 5 & 3 & 3 & 12 & 6 \\
\hline Physiotherapist & N/A & & 64 & 74 & $\mathrm{~N} / \mathrm{A}$ & \\
\hline GP & N/A & & N/A & & 93 & 45 \\
\hline Other ${ }^{b}$ & 31 & 11 & 5 & 6 & 26 & 13 \\
\hline
\end{tabular}

Note. For clarity, percentages are rounded to the nearest whole number. GP = general practitioner; N/A = not applicable.

a Indicates a statistically significant difference between the GPS and physiotherapists.

b Other practitioners that participants indicated they would refer to included arthritis nurse educator $(n=1)$, community exercise programme $(n=7)$, hydrotherapy $(n=2)$, osteopath $(n=2)$, personal trainer $(n=4)$, podiatry $(n=7)$, practice nurse $(n=6)$ and sports doctor $(n=2)$.

15.54, $p=0.0001)$. Both physiotherapists and GPs indicated that they would most commonly refer the person described in the vignette to the other group's profession, respectively. Considerably fewer participants indicated that they would consider referring the patient to another profession such as a dietitian, orthopaedic surgeon or pharmacist. Very few participants indicated they would refer the patient to a pain specialist $(2 \%)$ or a psychologist $(<1 \%)$.

Most indicated they would provide advice and education (98\%) and therapeutic exercise (92\%). In contrast, very few participants indicated that they would suggest intra-articular injection (7\%) or opioid-based analgesics (2\%). GPs' and physiotherapists' answers differed significantly for many (8 of 11) of their chosen treatment modalities for the person. Most of these significant differences reflect differences between scopes of practice of each profession.

Almost every participant (99\%) indicated that they would provide the patient with advice as part of their treatment (Table 3). The highest number of participants indicated that they would give the person advice about weight loss (87\%), pacing activities (81\%) and analgesic use (72\%). Significant differences occurred between the two professions for six of the 11 advice categories; again, these differences reflected differences in scopes of practice. Significantly more physiotherapists expected to see the person described in the case study more times for her OA $\left(X^{2}(4)\right.$ $=76.04, p=0.0001$ ).

\section{DISCUSSION}

The findings of this study suggest that first-line knee OA treatment knowledge held by the GPs and physiotherapists in this study are in line with core treatments recommended in best-practice guidelines (McAlindon et al., 2014 [Osteoarthritis Research Society International]; National Institute for Health and Care Excellence, 2015), and is influenced by their respective professional scopes of practice. While both groups suggested they would commonly refer patients with OA to the other group (i.e., GPs to physiotherapists or vice versa), referral to other health professions appear limited and may indicate the need for a Model of OA Care in New Zealand to facilitate better collaboration between healthcare professionals (Baldwin et al., 2017). Furthermore, this limited collaboration is reflected in patients' experience of OA treatment in New Zealand (Jolly et al., 2017; Larmer et al., 2019; McGruer et al., 2019). It was interesting to note that some participants indicated they would consider applying treatment modalities or advice that is not supported by best practice guidelines, such as acupuncture and rest (National Institute for Health and Care Excellence, 2015). 
Table 3

Vignette Beliefs And Referral Decisions

\begin{tabular}{|c|c|c|c|c|c|c|}
\hline \multirow[t]{3}{*}{ Characteristic } & \multicolumn{2}{|c|}{$\begin{array}{l}\text { All participants } \\
\quad(n=272)\end{array}$} & \multicolumn{2}{|c|}{$\begin{array}{c}\text { GPs } \\
(n=78)\end{array}$} & \multicolumn{2}{|c|}{$\begin{array}{c}\text { Physiotherapists } \\
(n=194)\end{array}$} \\
\hline & \multicolumn{6}{|c|}{ Answered 'Yes' } \\
\hline & $n$ & $\%$ & $n$ & $\%$ & $n$ & $\%$ \\
\hline $\begin{array}{l}\text { Would you be likely to refer this patient to another health } \\
\text { care professional? a }\end{array}$ & 172 & 63 & 64 & 82 & 108 & 56 \\
\hline \multicolumn{7}{|l|}{ Would you refer this woman to a...? } \\
\hline Dietitian & 52 & 19 & 14 & 18 & 38 & 20 \\
\hline Orthopaedic surgeon & 38 & 14 & 8 & 10 & 30 & 16 \\
\hline Pharmacist & 32 & 12 & 5 & 6 & 27 & 14 \\
\hline Support group & 28 & 10 & 9 & 12 & 19 & 10 \\
\hline Podiatrist a & 24 & 9 & 2 & 3 & 22 & 11 \\
\hline Rheumatologist & 17 & 6 & 2 & 3 & 15 & 5 \\
\hline Acupuncturist & 10 & 4 & 1 & 1 & 9 & 5 \\
\hline Exercise physiologist & 10 & 4 & 4 & 5 & 6 & 3 \\
\hline Occupational therapist & 10 & 4 & 3 & 4 & 7 & 4 \\
\hline Pain clinic & 6 & 2 & 0 & 0 & 5 & 3 \\
\hline Osteopath & 1 & $>1$ & 0 & 0 & 1 & $>1$ \\
\hline Psychologist & 1 & $>1$ & 0 & 0 & 1 & $>1$ \\
\hline Chiropractor & 0 & 0 & 0 & 0 & 0 & 0 \\
\hline GP & $\mathrm{N} / \mathrm{A}$ & & N/A & & 92 & 47 \\
\hline Physiotherapist & $\mathrm{N} / \mathrm{A}$ & & 57 & 73 & $\mathrm{~N} / \mathrm{A}$ & \\
\hline \multicolumn{7}{|l|}{ Once you have made your diagnosis, would you suggest...? } \\
\hline Advice and education & 267 & 98 & 75 & 96 & 192 & 99 \\
\hline Therapeutic exercises ${ }^{a}$ & 251 & 92 & 63 & 81 & 188 & 96 \\
\hline Ice or heat a & 138 & 51 & 20 & 26 & 118 & 61 \\
\hline Manual therapy a & 137 & 50 & 6 & 8 & 131 & 67 \\
\hline Prescription of simple analgesics ${ }^{a}$ & 126 & 46 & 76 & 97 & 50 & 25 \\
\hline Strapping or bracing a & 89 & 33 & 7 & 9 & 82 & 42 \\
\hline Acupuncture ${ }^{a}$ & 70 & 26 & 4 & 5 & 66 & 34 \\
\hline Prescription of non-steroidal anti-inflammatory drugs ${ }^{a}$ & 67 & 25 & 39 & 50 & 28 & 14 \\
\hline Rest $^{\mathrm{a}}$ & 30 & 11 & 8 & 10 & 22 & 11 \\
\hline An intra-articular injection of steroids or similar a & 20 & 7 & 16 & 21 & 4 & 2 \\
\hline Prescription of opioid-based analgesics ${ }^{a}$ & 6 & 2 & 5 & 6 & 1 & $>1$ \\
\hline Would you offer any advice as part of your treatment? & 270 & 99 & 78 & 100 & 192 & 99 \\
\hline \multicolumn{7}{|l|}{ Would you offer any advice about...? } \\
\hline Weight loss & 237 & 87 & 69 & 89 & 168 & 86 \\
\hline Pacing activities ${ }^{a}$ & 220 & 81 & 42 & 54 & 178 & 91 \\
\hline Analgesics ${ }^{a}$ & 196 & 72 & 65 & 83 & 131 & 67 \\
\hline Heat or ice ${ }^{a}$ & 159 & 58 & 28 & 36 & 131 & 67 \\
\hline Increasing level of activity ${ }^{a}$ & 150 & 55 & 32 & 41 & 118 & 61 \\
\hline Using a walking aid & 132 & 48 & 32 & 41 & 100 & 51 \\
\hline Nutrition & 105 & 39 & 27 & 35 & 78 & 40 \\
\hline The use of knee supports a & 90 & 33 & 18 & 23 & 72 & 37 \\
\hline Rest & 48 & 18 & 9 & 12 & 39 & 20 \\
\hline Avoiding painful movements & 40 & 15 & 12 & 15 & 28 & 14 \\
\hline Reducing activity levels a & 28 & 10 & 2 & 3 & 26 & 13 \\
\hline \multicolumn{7}{|l|}{ How often would you be likely to see this woman? } \\
\hline Once $^{a}$ & 6 & 2 & 4 & 5 & 2 & 1 \\
\hline 2-3 times & 86 & 32 & 52 & 67 & 34 & 18 \\
\hline $4-5$ times & 91 & 34 & 18 & 23 & 73 & 38 \\
\hline $6-7$ times & 50 & 18 & 1 & 1 & 49 & 25 \\
\hline$>7$ times & 39 & 14 & 3 & 4 & 36 & 19 \\
\hline
\end{tabular}

Note. For clarity, percentages are rounded to the nearest whole number. GP = general practitioner; N/A = not applicable.

a Indicates a statistically significant difference between the GPs and physiotherapists. 


\section{Demographic characteristics}

Participants included clinicians with a range of different experience levels, frequency of treating people with knee OA, employment settings and geographical locations. However, the small sample sizes (approximately $4 \%$ of New Zealand registered physiotherapists and $1 \%$ of GPs completed the survey) means that the findings cannot be considered representative of the treatment knowledge or self-reported referral behaviour of each profession. Considerably more physiotherapists participated in the study than GPs. Previous research has referred to the challenges of recruiting GPs to studies of this nature, citing causes for low research recruitment rates as survey fatigue and high workloads (Cottrell et al., 2015, 2017). It is possible that the length of the survey in the current study was a barrier to GP participation and future research needs to address these challenges to enhance recruitment of GPS.

\section{OA patient referral decisions}

Participants most commonly reported the three professions or services they refer people with OA to as radiology, orthopaedic surgery and Green Prescription (a publicly funded communitybased exercise and activity service). These findings are not surprising. First, $\mathrm{X}$-ray is still considered a critical diagnostic tool by some clinicians, despite current contradictory evidence and recommendations that suggest that imaging is unnecessary (National Institute for Health and Care Excellence, 2015). Imaging correlates poorly with symptoms and, in some cases, is harmful because it reinforces a purely mechanical view of the disease (Bunzli et al., 2019; O'Brien et al., 2019). Second, surgical joint replacement is common and effective for reducing pain (Hochberg et al., 2015; Leskinen et al., 2012).

In contrast, only a few participants indicated they would refer people with knee OA to dietitians, psychologists and occupational therapists. A high body-mass index score is a known risk factor for developing $\mathrm{OA}$ and an aggravating factor with OA (Barrow et al., 2019; Hochberg et al., 2015). Therefore, it would seem logical that referral to dietitians to help with weight loss, when appropriate, would be beneficial. Similarly, many people with OA describe the impact of the disease on their mental and emotional wellbeing (Bijsterbosch et al., 2009; Brembo et al., 2016; Sharma et al., 2016). Thus, engaging the services of a psychologist could be beneficial for these people. Limitations of activities of daily living and mobility are common, as is chronic fatigue (Hegarty et al., 2016; Murphy et al., 2013; Palmer, 2012). Hence, a benefit may be obtained from occupational therapy services to facilitate pacing and coping and the prescription of functional aids (Stukstette et al., 2012).

Three factors may explain the findings of clinicians' referral practices. First, GPs and physiotherapists may see little efficacy in these services or have a limited understanding of what these professions could offer people with OA. This limited knowledge is known to affect the referral of people with OA to conservative treatment programmes (Chevalier et al., 2004). Second, the current funding model in New Zealand does not typically facilitate referral for people with OA to these services because patients have to pay for these services. Cost and funding models are known to affect how clinicians in primary care services practise and refer (Stokes et al., 2017). Furthermore, Stokes et al. (2017) found that the current primary care funding model in New Zealand has led to the fragmentation of care for people living with chronic multi-morbidity. Third, the findings may be due to inadequate or limited communication between health professionals. If GPs and physiotherapists do not regularly practise with clinicians from these professions, they may not consider including these professions in an integrated or collaborative approach to OA treatment (Hall, 2005; Westby \& Backman, 2010).

\section{Vignette referral decisions and treatment knowledge} The results show that the participants supported first-line treatment practices in keeping with current best-practice recommendations for the treatment of people with knee OA (Fransen et al., 2015; McAlindon et al., 2014; Merashly \& Uthman, 2012). Advice and education and therapeutic exercise were the most popular interventions considered appropriate for the person described in the vignette, findings that are similar to previous research using this vignette (Holden et al., 2008). Moreover, this finding suggests that participants perceive value in therapeutic exercise for people with moderate knee OA. The most popular advice categories were weight loss, pacing activities and the use of analgesics. Again, these results imply that participants were conscious of the known benefits of these interventions (Atukorala et al., 2016; Bliddal et al., 2014; Mills et al., 2019; Poitras et al., 2010). Several significant differences were seen in the recommended treatments and advice given between the two professional groups (GPs and physiotherapists). However, most of these differences can be explained by differences in the scope of practice of each profession. For example, significantly more GPs advocated prescription of medication, whereas more physiotherapists advocated treatment such as pacing, therapeutic exercises or manual therapy.

There were three areas where the findings suggest knowledge that differed from clinical best practice. First, a notable percentage of participants indicated they would recommend management approaches (acupuncture [26\%] and rest [18\%]) not supported by current evidence (McAlindon et al., 2014 [Osteoarthritis Research Society International]; National Institute for Health and Care Excellence, 2015). These findings may suggest that further professional training is needed among GPs and physiotherapists to ensure consistent, best-evidence management is provided to people with OA in New Zealand.

Second, very few participants specified that they would refer the person to a dietitian, despite $86.9 \%$ of participants indicating the importance of providing advice about weight loss. Obesity is a known risk factor for developing knee OA (Barrow et al., 2019; Silverwood et al., 2015). Furthermore, weight loss is known to reduce disease progression in people with knee OA (Van Manen et al., 2012). Therefore, this result is somewhat surprising, and the reason for this finding is unclear. Possible explanations for these findings may relate to the limited funding of dietetic services in New Zealand, the perception that any healthcare professional can provide weight-loss advice, or that effective weight loss is too challenging for people with knee OA. Again, this finding suggests that considerably more research is needed in this area of OA treatment. 
Third, $14 \%$ of participants indicated that they would refer the patient to an orthopaedic surgeon, despite limited conservative treatment options being trialled first. While this is a relatively small percentage, it is still notable given that surgery is only considered appropriate after all conservative treatments have been attempted (National Institute for Health and Care Excellence, 2015). Furthermore, 64\% of participants indicated they usually referred people with OA to an orthopaedic surgeon. The reason for these findings is not apparent, but the results may reflect a perception that joint replacement surgery is inevitable for people with OA or the limited state-funded conservative treatment services available to people with $\mathrm{OA}$ in New Zealand (Baldwin et al., 2017; Bunzli et al., 2019; O'Brien et al., 2019).

\section{Strengths and limitations}

A strength of the study was the adaptation and use of an existing clinical vignette (Holden et al., 2008), which allowed for comparison with previous research.

The study had several limitations. Twice as many physiotherapists as GPs completed the survey. Therefore, the findings may be biased towards physiotherapists' beliefs and may not represent GPs' beliefs. The sample size was relatively small, meaning the findings may not represent the knowledge or practice decisions of the wider population of physiotherapists and GPs in New Zealand. The high survey dropout rate (7.8\%) may reflect survey fatigue and indicate that the survey was too long for some participants. Finally, while the clinical vignette provides insight into clinicians' knowledge and practice, the results may be biased by participants inadvertently reporting socially desirable responses. Therefore, the reported data should be considered with caution as they may not reflect actual clinical practice.

\section{CONCLUSION}

Treatment knowledge of a sample New Zealand GPs and physiotherapists reported providing care for people with knee OA that was mainly in keeping with current first-line evidencebased recommendations. However, few participants indicated they referred to other health professionals such as dietitians, and a proportion of practitioners support the use of treatments not recommended by best-practice guidelines. Systems need to be developed to facilitate greater referral practices between clinical services to assist weight loss, where appropriate, and the management of the psychological symptoms of OA. Furthermore, these findings add to the growing evidence that signals New Zealand needs a Model of OA Care.

\section{KEY POINTS}

1. The first-line knee OA treatment knowledge of New Zealand GPs and physiotherapists is generally in keeping with international treatment guidelines, particularly in terms of core treatments of education, exercise prescription and weight-loss advice.

2. Engagement with services to support weight loss for people with knee OA merits greater consideration.

3. Some participants indicated using treatments or providing advice not supported by current evidence (acupuncture or rest).

\section{DISCLOSURES}

No funding was obtained for this study. There are no conflicts of interest that may be perceived to interfere with or bias this study.

\section{PERIMISSIONS}

This study was granted ethical consent by the Auckland University of Technology Ethics Committee (reference number 16/284). There was no mechanism of identifying people who participated in the study, and the participant information explained that by submitting the questionnaire electronically, they were consenting for the data to be used for the study. No additional permissions are required for this manuscript.

\section{ACKNOWLEDGEMENTS}

The primary author would like to acknowledge the ongoing support of Arthritis New Zealand and the Auckland University of Technology with this research.

\section{ADDRESS FOR CORRESPONDENCE}

Daniel O'Brien, Department of Physiotherapy, School of Clinical Sciences, Auckland University of Technology, North Shore Campus, Akoranga Drive, Northcote, Auckland, New Zealand.

Email: dobrien@aut.ac.nz

\section{REFERENCES}

Ackerman, I. N., Bucknill, A., Page, R. S., Broughton, N. S., Roberts, C., Cavka, B., Schoch, P., \& Brand, C. A. (2015). The substantial personal burden experienced by younger people with hip or knee osteoarthritis. Osteoarthritis and Cartilage, 23(8), 1276-1284. https://doi.org/10.1016/j. joca.2015.04.008

Allen, K. D., Choong, P. F., Davis, A. M., Dowsey, M. M., Dziedzic, K. S., Emery, C., Hunter, D. J., Losina, E., Page, A. E., Roos, E. M., Skou, S. T., Thorstensson, C. A., van der Esch, M., \& Whittaker, J. L. (2016). Osteoarthritis: Models for appropriate care across the disease continuum. Best Practice \& Research Clinical Rheumatology, 30(3), 503-535. https:// doi.org/10.1016/j.berh.2016.09.003

Atukorala, I., Makovey, J., Lawler, L., Messier, S. P., Bennell, K., \& Hunter, D. J. (2016). Is there a dose-response relationship between weight loss and symptom improvement in persons with knee osteoarthritis? Arthritis Care \& Research, 68(8), 1106-1114. https://doi.org/10.1002/acr.22805

Baldwin, J., Briggs, A. M., Bagg, W., \& Larmer, P. J. (2017). An osteoarthritis model of care should be a national priority for New Zealand. New Zealand Medical Journal, 130(1467), 78-86.

Barrow, D. R., Abbate, L. M., Paquette, M. R., Driban, J. B., Vincent, H. K., Newman, C., Messier, S. P., Ambrose, K. R., \& Shultz, S. P. (2019). Exercise prescription for weight management in obese adults at risk for osteoarthritis: Synthesis from a systematic review. BMC Musculoskeletal Disorders, 20, 610. https://doi.org/10.1186/s12891-019-3004-3

Bennell, K. (2013). Physiotherapy management of hip osteoarthritis. Journal of Physiotherapy, 59(3), 145-157. https://doi.org/10.1016/S18369553(13)70179-6

Bennell, K. L., Dobson, F., \& Hinman, R. S. (2014). Exercise in osteoarthritis: Moving from prescription to adherence. Best Practice \& Research Clinical Rheumatology, 28(1), 93-117. https://doi.org/10.1016/j.berh.2014.01.009 
Bijsterbosch, J., Scharloo, M., Visser, A. W., Watt, I., Meulenbelt, I., Huizinga, T. W. J., Kaptein, A. A., \& Kloppenburg, M. (2009). Illness perceptions in patients with osteoarthritis: Change over time and association with disability. Arthritis Care \& Research, 61(8), 1054-1061. https://doi. org/10.1002/art.24674

Bliddal, H., Leeds, A. R., \& Christensen, R. (2014). Osteoarthritis, obesity and weight loss: Evidence, hypotheses and horizons - a scoping review. Obesity Reviews, 15(7), 578-586. https://doi.org/10.1111/obr.12173

Brembo, E. A., Kapstad, H., Eide, T., Månsson, L., Van Dulmen, S., \& Eide, H. (2016). Patient information and emotional needs across the hip osteoarthritis continuum: A qualitative study. BMC Health Services Research, 16, 88. https://doi.org/10.1186/s12913-016-1342-5

Brosseau, L., Wells, G. A., Pugh, A. G., Smith, C. A., Rahman, P., Àlvarez Gallardo, I. C., Toupin-April, K., Loew, L., De Angelis, G., Cavallo, S., Taki, J., Marcotte, R., Fransen, M., Hernandez-Molina, G., Kenny, G. P., Regnaux, J.-P., Lefevre-Colau, M.-M., Brooks, S., Laferriere, L., ... Longchamp, G. (2016). Ottawa Panel evidence-based clinica practice guidelines for therapeutic exercise in the management of hip osteoarthritis. Clinical Rehabilitation, 30(10), 935-946. https://doi. org/10.1177/0269215515606198

Bunzli, S., O’Brien, P., Ayton, D., Dowsey, M., Gunn, J., Choong, P., \& ManskiNankervis, J.-A. (2019). Misconceptions and the acceptance of evidencebased nonsurgical interventions for knee osteoarthritis. A qualitative study. Clinical Orthopaedics and Related Research, 477(9), 1975-1983. https:// doi.org/10.1097/CORR.0000000000000784

Chevalier, X., Marre, J. P., de Butler, J., \& Hercek, A. (2004). Questionnaire survey of management and prescription of general practitioners in knee osteoarthritis: A comparison with 2000 EULAR recommendations. Clinical and Experimental Rheumatology, 22(2), 205-212.

Cottrell, E., Foster, N. E., Porcheret, M., Rathod, T., \& Roddy, E. (2017). GPs' attitudes, beliefs and behaviours regarding exercise for chronic knee pain: A questionnaire survey. BMJ Open, 7(6), e014999. https://doi.org/10.1136/ bmjopen-2016-014999

Cottrell, E., Roddy, E., Rathod, T., Thomas, E., Porcheret, M., \& Foster, N. E. (2015). Maximising response from GPs to questionnaire surveys: Do length or incentives make a difference? BMC Medical Research Methodology, 15, 3. https://doi.org/10.1186/1471-2288-15-3

Cross, M., Smith, E., Hoy, D., Nolte, S., Ackerman, I., Fransen, M., Bridgett, L., Williams, S., Guillemin, F., Hill, C. L., Laslett, L. L., Jones, G., Cicuttini, F., Osborne, R., Vos, T., Buchbinder, R., Woolf, A., \& March, L. (2014). The global burden of hip and knee osteoarthritis: Estimates from the Global Burden of Disease 2010 study. Annals of the Rheumatic Diseases, 73(7), 1323-1330. https://doi.org/10.1136/annrheumdis-2013-204763

Deloitte Access Economics. (2018). The economic cost of arthritis in New Zealand in 2018: Arthritis New Zealand. https://www.arthritis.org. nz/wp-content/uploads/2018/09/Economic-cost-of-Arthritis-in-NewZealand-2018.pdf

Evans, S. C., Roberts, M. C., Keeley, J. W., Blossom, J. B., Amaro, C. M., Garcia, A. M., Stough, C. O., Canter, K. S., Robles, R., \& Reed, G. M. (2015). Vignette methodologies for studying clinicians' decision-making: Validity, utility, and application in ICD-11 field studies. International Journal of Clinical and Health Psychology, 15(2), 160-170. https://doi. org/10.1016/j.ijchp.2014.12.001

Fransen, M., McConnell, S., Harmer, A. R., Van der Esch, M., Simic, M., \& Bennell, K. L. (2015). Exercise for osteoarthritis of the knee. Cochrane Database of Systematic Reviews. https://doi.org/10.1002/14651858. CD004376.pub3

Hall, P. (2005). Interprofessional teamwork: Professional cultures as barriers. Journal of Interprofessional Care, 19(Suppl. 1), 188-196. https://doi. org/10.1080/13561820500081745

Healey, E. L., Afolabi, E. K., Lewis, M., Edwards, J. J., Jordan, K. P., Finney, A., Jinks, C., Hay, E. M., \& Dziedzic, K. S. (2018). Uptake of the NICE osteoarthritis guidelines in primary care: A survey of older adults with joint pain. BMC Musculoskeletal Disorders, 19, 295. https://doi.org/10.1186/ s12891-018-2196-2
Hegarty, R. S. M., Treharne, G. J., Stebbings, S., \& Conner, T. S. (2016). Fatigue and mood among people with arthritis: Carry-over across the day. Health Psychology, 35(5), 492-499. https://doi.org/10.1037/hea0000321

Hochberg, M. C., Silman, A., Smolen, J., Weinblatt, M., \& Weisman, M. (Eds.). (2015). Rheumatology (6th ed., Vol. 1-2). Elsevier.

Holden, M. A., Nicholls, E. E., Hay, E. M., \& Foster, N. E. (2008). Physical therapists' use of therapeutic exercise for patients with clinical knee osteoarthritis in the United Kingdom: In line with current recommendations? Physical Therapy, 88(10), 1109-1121. https://doi org/10.2522/ptj.20080077

Hunter, D. J. (2011). Lower extremity osteoarthritis management needs a paradigm shift. British Journal of Sports Medicine, 45(4), 283-288. https:// doi.org/10.1136/bjsm.2010.081117

Hunter, D. J. (2017). Osteoarthritis management: Time to change the deck. The Journal of Orthopaedic and Sports Physical Therapy, 47(6), 370-372. https://doi.org/10.2519/jospt.2017.0605

Jolly, J., Bassett, S. F., O’Brien, D., Parkinson, C., \& Larmer, P. J. (2017). An exploration of the sequence and nature of treatment options available to people living with osteoarthritis of the hip and/or knee within a New Zealand context. New Zealand Journal of Physiotherapy, 45(2), 90-95.

Larmer, P. J., Bennett, K., Baldwin, J. N., Bassett, S., \& O’Brien, D. W. (2019) Quality indicators for hip and knee osteoarthritis management in New Zealand: A patient survey. New Zealand Journal of Physiotherapy, 47(3), 183-192. https://doi.org/10.15619/NZJP/47.3.06

Larmer, P. J., Reay, N. D., Aubert, E. R., \& Kersten, P. (2014). Systematic review of guidelines for the physical management of osteoarthritis. Archives of Physical Medicine and Rehabilitation, 95(2), 375-389. https:// doi.org/10.1016/j.apmr.2013.10.011

Leskinen, J., Eskelinen, A., Huhtala, H., Paavolainen, P., \& Remes, V. (2012). The incidence of knee arthroplasty for primary osteoarthritis grows rapidly among baby boomers: A population-based study in Finland. Arthritis \& Rheumatism, 64(2), 423-428. https://doi.org/10.1002/art.33367

McAlindon, T. E., Bannuru, R. R., Sullivan, M. C., Arden, N. K., Berenbaum, F., Bierma-Zeinstra, S. M., Hawker, G. A., Henrotin, Y., Hunter, D. J., Kawaguchi, H., Kwoh, K., Lohmander, S., Rannou, F., Roos, E. M., \& Underwood, M. (2014). OARSI guidelines for the non-surgical management of knee osteoarthritis. Osteoarthritis and Cartilage, 22(3), 363-388. https://doi.org/10.1016/j.joca.2014.01.003

McGruer, N., Larmer, P. J., Baldwin, J., \& Ruakere, T. (2019). Māori lived experiences of osteoarthritis: A qualitative study guided by Kaupapa Māori principles. Journal of Primary Health Care, 11(2), 128-137. https://doi. org/10.1071/HC18079

Merashly, M., \& Uthman, I. (2012). Management of knee osteoarthritis: An evidence-based review of treatment options. Lebanese Medical Journal, $60(4), 237-242$.

Mills, K., Hübscher, M., O'Leary, H., \& Moloney, N. (2019). Current concepts in joint pain in knee osteoarthritis. Der Schmerz, 33, 22-29. https://doi. org/10.1007/s00482-018-0275-9

Murphy, S. L., Alexander, N. B., Levoska, M., \& Smith, D. M. (2013). Relationship between fatigue and subsequent physical activity among older adults with symptomatic osteoarthritis. Arthritis Care \& Research, 65(10), 1617-1624. https://doi.org/10.1002/acr.22030

National Institute for Health and Care Excellence. (2015). Osteoarthritis quality standard [QS87]. https://www.nice.org.uk/guidance/qs87/ resources/osteoarthritis-pdf-2098913613253

O'Brien, D. (2018). Exploration of the osteoarthritis health, illness and treatment beliefs of New Zealanders with hip and/or knee osteoarthritis and the clinicians who treat the condition [PhD, Auckland University of Technology]. http://hdl.handle.net/10292/11468

O'Brien, D. W., Chapple, C. M., Baldwin, J. N., \& Larmer, P. J. (2019). Time to bust common osteoarthritis myths. New Zealand Journal of Physiotherapy, 47(1), 18-24. https://doi.org/10.15619/NZJP/47.1.03

Pallant, J. (2011). SPSS survival manual: A step by step guide to data analysis using the SPSS program (4th ed.). Allen \& Unwin. 
Palmer, K. T. (2012). Occupational activities and osteoarthritis of the knee. British Medical Bulletin, 102(1), 147-170. https://doi.org/10.1093/bmb/ Ids012

Peabody, J. W., Luck, J., Glassman, P., Jain, S., Hansen, J., Spell, M., \& Lee M. (2004). Measuring the quality of physician practice by using clinical vignettes: A prospective validation study. Annals of Internal Medicine, 141(10), 771-780. https://doi.org/10.7326/0003-4819-141-10200411160-00008

Poitras, S., Rossignol, M., Avouac, J., Avouac, B., Cedraschi, C., Nordin, M., Rousseaux, C., Rozenberg, S., Savarieau, B., Thoumie, P., Valat, J.-P., Vignon, E., \& Hilliquin, P. (2010). Management recommendations for knee osteoarthritis: How usable are they? Joint, Bone, Spine, 77(5), 458-465. https://doi.org/10.1016/j.jbspin.2010.08.001

Sharma, A., Kudesia, P., Shi, Q., \& Gandhi, R. (2016). Anxiety and depression in patients with osteoarthritis: Impact and management challenges. Open Access Rheumatology: Research and Reviews, 8, 103-113. https://doi. org/10.2147/OARRR.S93516

Silverwood, V., Blagojevic-Bucknall, M., Jinks, C., Jordan, J. L., Protheroe, J., \& Jordan, K. P. (2015). Current evidence on risk factors for knee osteoarthritis in older adults: A systematic review and meta-analysis. Osteoarthritis and Cartilage, 23(4), 507-515. https://doi.org/10.1016/j joca.2014.11.019
Stokes, T., Tumilty, E., Doolan-Noble, F., \& Gauld, R. (2017). Multimorbidity, clinical decision making and health care delivery in New Zealand primary care: A qualitative study. BMC Family Practice, 18, 51. https://doi. org/10.1186/s12875-017-0622-4

Stukstette, M., Hoogeboom, T. J., Ruiter, R. de, Koelmans, P., Veerman, E., Broeder, A. A., den Cats, H., Bijlsma, J. W., Dekker, J., \& van den Ende, C. H. M. (2012). A multidisciplinary and multidimensional intervention for patients with hand osteoarthritis. Clinical Rehabilitation, 26(2), 99-110 https://doi.org/10.1177/0269215511417739

Van Manen, M. D., Nace, J., \& Mont, M. A. (2012). Management of primary knee osteoarthritis and indications for total knee arthroplasty for general practitioners. Journal of the American Osteopathic Association, 112(11), 709-715.

Westby, M. D. \& Backman, C. L. (2010). Patient and health professional views on rehabilitation practices and outcomes following total hip and knee arthroplasty for osteoarthritis: A focus group study. BMC Health Services Research, 10, 119. https://doi.org/10.1186/1472-6963-10-119

morning and after staying in one position for too long. She finds some relief from an anti-inflammatory gel and takes up to three 200-mg ibuprofen tablets per day.

Despite not having a radiograph, she feels her problem is due to arthritis, as her father had this. This is the first time that she has consulted with a health professional about the problem, and she is optimistic about its outcome. On examination, the left knee has a mild effusion and a valgus alignment. Flexion is limited and the quadriceps femoris muscles are weak. The joint line is tender on palpation. No other examination findings are remarkable. 